\title{
Disparity in Maternal Health Services Among the Different Geopolitical Zones in Nigeria
}

\author{
Abubakar Sadiq Umar \\ Walden University \\ Chinaro Kennedy \\ Walden University \\ Hebatullah Tawfik \\ Walden University \\ Daniel M. N. Okenu \\ Walden University
}

\begin{abstract}
Although the use of antenatal and other skilled maternal health delivery services in Nigeria was reported to be on the increase, this research explored whether geopolitical zone of residence and place of domicile are associated with the number of antenatal visits and place of delivery. A quantitative cross-sectional study based on secondary data from the Demographic and Health Survey was used to examine the relationship between women's geopolitical zone of residence, place of domicile (rural/urban), and the number of antenatal visits (categorized as fewer than four or four or more) and delivery (home or health facility). A total of 33,385 women aged 15-49 years were recruited from 888 clusters spread across all the 36 states and the federal capital territory of Nigeria using a stratified two stage proportionate to size cluster design. A higher proportion of women from the South West and North Central zones had made four or more antenatal care visits compared to the other geopolitical zones. The difference was statistically significant even after controlling for differences in education, income, ethnicity, religion, autonomy, and place of domicile (adjusted odd ratio $=2.062 ; 95 \%$ confidence interval $[1.897,2.241] ; p<.05)$. Healthcare policy makers should consider the potential impact of geopolitical zones and place of domicile to enable the development of an all-inclusive strategy to robustly address maternal health services in Nigeria.
\end{abstract}

Keywords: antenatal care, skilled delivery, regional variation, Nigeria 


\section{Introduction}

The major objective of a comprehensive maternal health care system is to provide primary, secondary and tertiary levels of care to women in their child-bearing age (World Health Organization [WHO], 2005). It entails the provision of health promotion services including health education, specific preventive measures (nutrition, iron and folic acid supplementation, antimalarial, immunization), early detection and diagnosis of diseases/conditions during antenatal, natal, and postnatal care. These conditions may include anemia, congenital disease, preeclampsia, eclampsia, and obstructed labor (WHO, 2005). Other health promotion services are rehabilitation support in cases of postnatal psychosis and vesicovaginal fistula, and family planning counseling (WHO, 2005). The goal is not only to detect abnormalities during pregnancy and delivery, but also to facilitate the adoption of attitudes and behaviors that are health promotive and reduces the potential of complicated pregnancies and poor pregnancy outcome (WHO, 2011).

Several studies have demonstrated a high correlation between maternal morbidity and mortality with women's use of antenatal, natal, and postnatal services, including family planning (Ahmed, Creanga, Gillespie, \& Tsui, 2010; Nieburg, 2012; Wang, Alva, Wang, \& Fort, 2011). The incidence of congenital malformation, severe birth asphyxia, preterm deliveries, stillbirths, and maternal and neonatal mortality were more commonly seen among women who did not start ante natal visits early, had not been regular for antenatal care (ANC) visits, or had received poor quality of maternal health services (MHS; WHO, 2015; WHO, UNICEF, United Nations Population Fund, \& the World Bank, 2010). It is against this background that the WHO assembled a group of experts between the last quarter of 2015 to the end of first quarter of 2016 that came up with evidenced-based interventions that will lead to the reduction of maternal and neonatal deaths. One of the outcomes of the said consultations led WHO in the later part of 2016 to revise the recommendation on the number of ANC visits from four to eight contacts (WHO, 2016a). The implementation of the new recommendation emphasized the need for each country to revitalize and or establish communitybased outreach maternity services and the use of untrained community based health workers (WHO, 2016a). For these approaches to be implemented, there is the need for time to revise health systemrelated policies, marshal resources such as workers and vehicles, build capacity of all involved and conduct massive community sensitization on the benefits of the new recommendation. These issues underscored the fact that the new recommendation is still at its infancy and hence, we decided to assess the use of MHS services using the previous recommended four ANC visits.

Furthermore, not all pregnant women attend ANC; of those who attend, many fail to complete the recommended four visits. Many women give birth in homes (Nakua et al., 2015; Shiferaw, Spigt, Godefrooij, Melkamu, \& Tekie, 2013; WHO, 2016b) and/or are attended by unskilled health workers (Fapohunda \& Orobaton, 2013, 2014). The proportion of pregnant women that had made at least a single ANC visit between 2005 and 2012 worldwide stood at 81\% (WHO, 2013). However, only 55\% had made the recommended four ANC visits indicating suboptimal use of ANC services (WHO, 2013). Among the six WHO regions, only the Americas and European regions have achieved $86 \%$ and $80 \%$, respectively, regarding the proportion of women who have attended four ANC visits (WHO, 2013). This is in contrast with the African and Eastern Mediterranean regions, in which less than half of all pregnant women had attended four ANC visits between 2005 and 2012 (WHO, 2013). One of the reasons for the low number of ANC visits was because less than $50 \%$ of all pregnant women commence ANC visit in the first trimester. In some countries of Africa, the figure is as low as $10 \%$. For instance, of the women who reported having at least one ANC visit in Malawi, only half did so in the first trimester. Similarly, in Senegal, more than $90 \%$ of pregnant women were reported to have had their first ANC visit in the third trimester. Without doubt, such practices will not enhance the 
attainment of the primary objective of ANC aimed to identify and commence early management of high-risk pregnancies (Ezugwu, Agu, Nwoke, \& Ezugwu, 2014; Wang et al., 2011).

In Nigeria, 25\%, 64\%, and 11\% of pregnant women had their first ANC in the first, second, and third trimesters, respectively, suggesting that the majority of women commenced ANC after 5 months (Wang et al., 2011). This could have led to the late identification of complicated pregnancies and could be partially responsible for Nigeria being among the top 11 countries with the highest maternal mortality rates in the world (WHO et al., 2010).

Furthermore, only $34 \%$ of deliveries are supervised by trained personnel (WHO, 2013), and many women come in with life-threatening conditions (Fawole et al., 2012; Garba \& Umar, 2013). This means that nearly two thirds of all births were conducted in homes or in health facilities that are not well equipped and are not supported by individuals with sufficient technical competence. The main research question that was addressed in the current study was whether Nigerian women's characteristics as measured by geopolitical zone of residence and place of domicile (rural/urban) are associated with use of MHS as measured by the number of antenatal visits and place of delivery? The study has potential to bring about social change through identifying appropriate interventions that may improve the access and use of MHS that ultimately bring about the desired use of MHS and positive pregnancy outcomes. Health policy makers and implementers are likely to benefit from the study by gaining better understanding of the basic barriers that influence women's use of MHS and how it affects pregnancy outcomes.

\section{Method}

Nigeria is the most populous country in Africa accounting for one fifth of the continent population. It has a total population of 143 million based on the estimates from the 2006 national census with a population density of 153 people per square kilometer (National Population Commission \& ICF Macro, 2009). Women of child bearing age were estimated to be 31.4 million with an estimated annual number of pregnancies and surviving infants of 8.3 million and 7.3 million, respectively kilometer (National Population Commission \& ICF Macro, 2009). The country operates as a federation with federal, state, and local governments headed by democratically elected executive and legislative assemblies at all levels. There are 774 local government areas spread across 36 states and a federal capital territory (Figure 1). The 36 states were clustered into six geopolitical zones based on historical and sociocultural similarities. 


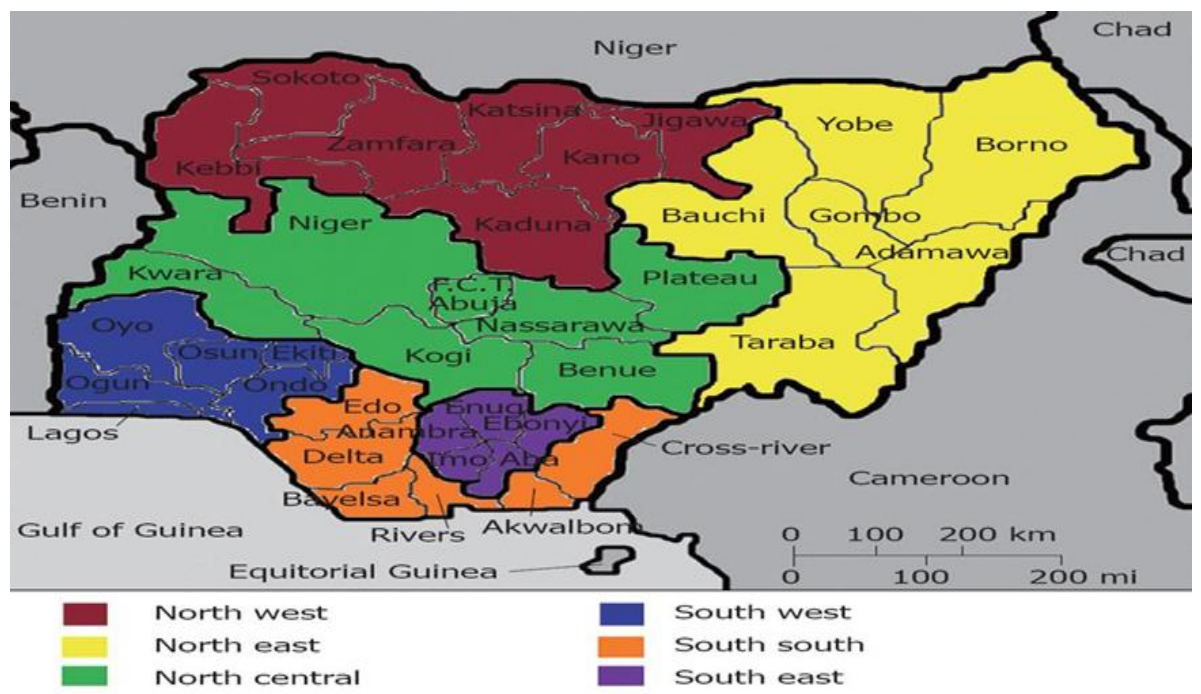

Figure 1. Map of Nigeria Showing States and Geopolitical Zones

In the present study, a secondary data analysis, using a quantitative cross-sectional study design, was used to examine the association between Nigerian women's geopolitical zone of residence (North East, North West, North Central, South East, South West, and South South), place of domicile (rural/urban), the use of MHS as measured by the number of antenatal visits (fewer than four or four or more), and place of delivery (home or health facility). Permission to access the Demographic and Health Survey (DHS) data for Nigeria was obtained from ORC Macro and ICF International based in Calverton, Maryland. The DHS data set has a large sample size of 33,385 women aged 15-49 years that strengthened the external validity of the findings (Szklo \& Nieto, 2014) because the DHS data drew participants using weighted probability sampling methods (National Population Commission \& ICF Macro, 2009). Details of the survey methods can found in an online survey report (National Population Commission \& ICF Macro, 2009). The present study also received approval from the Institutional Review Board of Walden University in Minneapolis, Minnesota. The Andersen health behavior model (Andersen, 1995; Andersen \& Newman, 2005) provided the theoretical framework for this study. The model consists of constructs that describe, among other factors, how geographical characteristics of women influence the use of antenatal and delivery services.

The outcome variables used for this study were dichotomous categorical (had four ANC visits/had fewer than four ANC visits; delivered at home/delivered in hospital). Multivariate logistic regression models were developed for (a) ANC visits categorized as fewer than four visits and four or more number of ANC visits; and (b) place of delivery (home or institutional). Variables that were included in the model were selected based on previous research and conceptual pathways for the association. Variables that were found to have significant statistical association from bivariate Pearson chisquare statistic were analyzed in the regression models. A similar approach was used using the 2003 and 2008 DHS data to identify factors associated with the use of Maternal and Child Health Care Services in Nigeria (Antai, 2009; Fapohunda \& Orobaron, 2014). 


\section{Results}

Out of the 33,385 women aged 15-49 years who have participated in the DHS, only 31,985 (95.8\%) individuals' data on the number of ANC visits were used in the analysis of our study. The majority of the study sample was from the northern part of Nigeria, accounting for $60.4 \%$ of all participants. The North West and South East zones had the highest (22\%) and lowest (10.6\%) proportion of participants, respectively. Women from the North West and South West zones had the lowest (13.2\%) and highest (38\%) proportion of women who had made four or more ANC visits in their last pregnancy before the survey, respectively (Figure 2). The proportion of women who had made four or more ANC visits in the other zones in order of magnitude is as follows: North Central (29\%), South East (26\%), South South (26\%), and North East (22.9\%; see Figure 2).

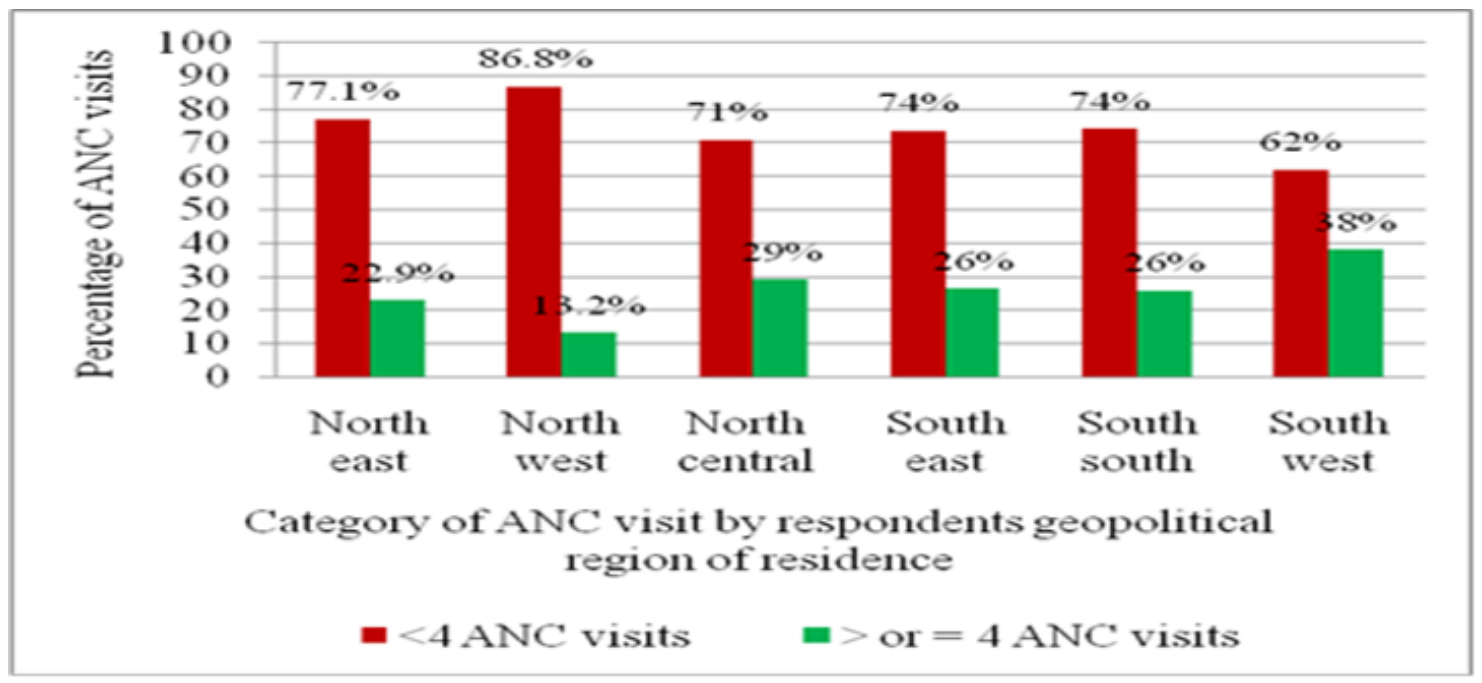

Figure 2. Regional Distribution of the Participants and Antenatal Visits

Women living in rural areas constituted $68.8 \%$ of the sample, and only $24.3 \%$ of these women had four or more ANC visits (Table 1). Less than a quarter of the respondents reported that distance was a major obstacle to access and use of MHS, with only $28.1 \%$ of these women making four or more ANC visits (Table 1). 
Table 1. Social Characteristics of Respondents

\begin{tabular}{lccc}
\hline & & \multicolumn{2}{c}{ Number of ANC Visits } \\
\cline { 3 - 4 } Independent Variable & Proportion of Sample (\%) & $\begin{array}{c}\text { Few Than } \\
\text { Four }\end{array}$ & $\begin{array}{c}\text { Four or } \\
\text { More }\end{array}$ \\
\hline Place of domicile & & & \\
$\quad$ Rural & 68.8 & 78.6 & 21.4 \\
$\quad$ Urban & 31.2 & 67.2 & 32.8 \\
Distance to health facility & & & \\
$\quad$ <5 km radius from home & 76.1 & 68.7 & 31.3 \\
$\quad>5$ km radius from home & 23.9 & 71.9 & 28.1 \\
Access to media & & & \\
$\quad$ Never/rarely & 49.7 & 60.2 & 19.8 \\
Almost/always & 50.3 & 69.9 & 30.1 \\
\hline
\end{tabular}

Regarding the source of information on MHS, only $50.3 \%$ of the respondents have regular access to electronic and print media. Women who have no access to the media have a lower use of ANC rate (19.8\%) compared to those who have access to the media (30.1\%; Table 1).

Comparison of use of MHS among the six geopolitical zones indicated that the women from the South West zone followed by the North Central zone were more likely to have four or more ANC visits, whereas the North East and the North West had the lowest proportion of women who had made the recommended ANC visits (Table 2$)$. This association was statistically significant $\left(\chi^{2}=1,020.307 ; d f=\right.$ $5 ; p<.001)$ and the women from the South West had higher odds of making four or more ANC visits compared to the North East (unadjusted odds ratio [OR unadjusted] $=1.534 ; 95 \%$ confidence interval $[\mathrm{CI}]$ [1.288, 1.827]; $p<.0001)$. A significant effect was observed upon controlling for differences in education, income, ethnicity, religion, autonomy, and place of domicile (adjusted odds ratio $\left[O R_{\text {adjusted }}\right]=2.062 ; 95 \%$ CI [1.897, 2.241]; $p<.05$; Table 2).

Table 2. Association Between Women's Geopolitical Zone of Residence and the Number of Antenatal Care (ANC) Visits

\begin{tabular}{|c|c|c|c|c|c|c|}
\hline \multirow[b]{2}{*}{$\begin{array}{l}\text { Geopolitical } \\
\text { Region }\end{array}$} & \multicolumn{2}{|c|}{$\begin{array}{c}\text { ANC Visits } \\
(n=31,985)\end{array}$} & \multirow{2}{*}{$\begin{array}{c}\text { Bivariate } \\
\text { Analysis } \\
\text { Pearson's } \\
\chi^{2} \\
\end{array}$} & \multicolumn{3}{|c|}{ Multivariate Logistic Regression Analysis } \\
\hline & $\begin{array}{c}\text { Fewer } \\
\text { Than Four }\end{array}$ & $\begin{array}{c}\text { Four or } \\
\text { More }\end{array}$ & & $\begin{array}{c}O R_{\text {unadjusted }} \\
{[95 \% \mathrm{CI}]}\end{array}$ & $\begin{array}{l}O R_{\text {adjusted }} \\
{[95 \% \mathrm{CI}]}\end{array}$ & $p$ \\
\hline North East & 4,751 & 1,413 & $.001^{*}$ & 1.000 & 1.000 & \\
\hline North West & 6,091 & 930 & & $\begin{array}{c}0.513 \\
{[0.469,0.562]}\end{array}$ & $\begin{array}{c}0.404 \\
{[0.356,0.458]}\end{array}$ & .101 \\
\hline North Central & 4,346 & 1,779 & & $\begin{array}{c}1.376 \\
{[1.269,1.493]}\end{array}$ & $\begin{array}{c}1.017 \\
{[0.906,1.142]}\end{array}$ & .771 \\
\hline South East & 2,503 & 891 & & $\begin{array}{c}1.197 \\
{[1.086,1.319]}\end{array}$ & $\begin{array}{c}1.098 \\
{[0.860,1.402]}\end{array}$ & .451 \\
\hline South South & 3,351 & 1,163 & & $\begin{array}{c}1.167 \\
{[1.067,1.276]}\end{array}$ & $\begin{array}{c}0.817 \\
{[0.691,0.966]}\end{array}$ & .180 \\
\hline South West & 2,955 & 1,812 & & $\begin{array}{c}2.062 \\
{[1.897,2.241]}\end{array}$ & $\begin{array}{c}1.534 \\
{[1.288,1.827]}\end{array}$ & $.001^{*}$ \\
\hline
\end{tabular}

Note. $O R=$ odds ratio; $\mathrm{CI}=$ confidence interval. Variables adjusted in the model: education, income, ethnicity, religion, autonomy, and place of domicile.

${ }^{*}$ Significant at the .05 level. 
The use of delivery services by geopolitical zones indicated that the three southern zones had a higher proportion of institutional deliveries ranging between $48.6 \%$ in the South South zone to $77 \%$ in the South West. While in the three northern geopolitical zones, the proportion of institutional deliveries lies between $8.5 \%$ in the North East zone to $42.6 \%$ in the North Central zone. The variation between the six geopolitical zones was found to be statistically significant $\left(\chi^{2}=5,121.03 ; d f\right.$ $=5 ; p<.001)$. In particular, women from the South East, South South, and South West zones were 15,5 , and 20 times more likely to use institutional delivery services compared to those from the North East zone (Table 3). However, after controlling for covariates (education, income, ethnicity, religion, and autonomy), this association only remained statistically significant for women in the South South region, who remained more likely to use institutional facilities compared to women in the North East zone $\left(O R_{\text {adjusted }}=1.69 ; 95 \%\right.$ CI $\left.[1.049,2.581]\right)$.

Table 3. Association Between Women's Geopolitical Zone of Residence and Place of Delivery

\begin{tabular}{|c|c|c|c|c|c|c|}
\hline \multirow[b]{2}{*}{$\begin{array}{l}\text { Geopolitical } \\
\text { Region }\end{array}$} & \multicolumn{2}{|c|}{$\begin{array}{r}\text { Place of Delivery } \\
(n=17,949) \\
\end{array}$} & \multirow{2}{*}{$\begin{array}{c}\text { Bivariate } \\
\text { Analysis } \\
\text { Pearson's } \\
\chi^{2} \\
\end{array}$} & \multicolumn{3}{|c|}{ Multivariate Logistic Regression Analysis } \\
\hline & Home & Facility & & $\begin{array}{l}\text { OR unadjusted } \\
{[95 \% \mathrm{CI}]}\end{array}$ & $\begin{array}{l}O R_{\text {adjusted }} \\
{[95 \% \mathrm{CI}]}\end{array}$ & $p$ \\
\hline North East & 3,403 & 564 & $.001^{*}$ & 1.000 & 1.000 & \\
\hline North West & 4,448 & 414 & & $\begin{array}{c}0.562 \\
{[0.491,0.642]}\end{array}$ & $\begin{array}{c}0.959 \\
{[0.614,1.498]}\end{array}$ & .855 \\
\hline North Central & 1,917 & 1,420 & & $\begin{array}{c}4.469 \\
{[3.994,5.001]}\end{array}$ & $\begin{array}{c}1.147 \\
{[0.811,1.621]}\end{array}$ & .439 \\
\hline South East & 417 & 1,033 & & $\begin{array}{c}14.947 \\
{[12.986,17.27]}\end{array}$ & $\begin{array}{c}0.835 \\
{[0.425,1.639]}\end{array}$ & .601 \\
\hline South South & 1,073 & 1,014 & & $\begin{array}{c}5.702 \\
{[5.038,6.453]}\end{array}$ & $\begin{array}{c}1.645 \\
{[1.049,2.581]}\end{array}$ & $.030^{*}$ \\
\hline South West & 517 & 1,729 & & $\begin{array}{c}20.178 \\
{[17.672,23.04]}\end{array}$ & $\begin{array}{c}1.419 \\
{[0.918,2.193]}\end{array}$ & .016 \\
\hline
\end{tabular}

Note. $O R=$ odds ratio; $\mathrm{CI}=$ confidence interval. Variables adjusted in the model: education, income, ethnicity, religion, availability of skilled health worker, and place of domicile.

* Significant at the .05 level.

Place of domicile has shown a significant statistical association with the number of ANC visits $\left(\chi^{2}=\right.$ 473.858; $d f=1 ; p<.001)$. Women living in urban areas have higher chances of using ANC services compared to their counterparts in rural $\left(O R_{\text {unadjusted }}=1.79 ; 95 \%\right.$ CI $\left.[1.698,1.886]\right)$. Following the control of covariates (education, income, ethnicity, religion, and autonomy), women living in urban centers are more likely to make the recommended ANC visits compared to rural women $\left(O R_{\text {adjusted }}=\right.$ $1.386 ; 95 \%$ CI $[1.256,1.491])$.

There is a significant statistical association between place of residence and the place of delivery $\left(\chi^{2}=\right.$ $2,020.54 ; d f=1 ; p<.001)$. Urban women are more likely to use modern delivery service compared to their rural counterparts $\left(O R_{\text {unadjusted }}=4.708 ; 95 \%\right.$ CI [4.389, 5.05]). Following the control of covariates (education, income, ethnicity, religion, and autonomy), urban women have $11 \%$ higher likelihood of giving birth in a health facility compared to their rural colleagues; however, this finding was not statistically significant $\left(O R_{\text {adjusted }}=1.115 ; 95 \%\right.$ CI $\left.[0.853,1.456]\right)$. 


\section{Discussion}

In the current study, geopolitical region of residence showed the widest variation in the use of MHS and pregnancy outcomes. The analysis of use of MHS by geopolitical zone provided a composite effect of individual and community level factors such as distance, availability of skilled health workers, ethnicity, religion, marital status, autonomy, education, occupation, and family wealth index. The southern zones of Nigeria have a higher proportion of women who had four or more ANC visits and institutional deliveries. Women from the North West and North East geopolitical zones had the lowest proportions for both ANC visits and institutional deliveries.

The only part of northern Nigeria that stood at par with the southern zones is the North Central zone, which recorded the second highest proportion of women who had made four or more ANC visits. This finding is consistent with areas with the highest maternal and infant mortality rates, high poverty levels, and low women's literacy levels (National Population Commission \& ICF Macro, 2009; Health Reform Foundation of Nigeria, 2007; UNICEF, 2009). Further, this variation between the various geopolitical zones of Nigeria reflects the availability, comprehensiveness, affordability, and the quality of MHS and a reflection of the attitudes and beliefs of the population toward the use of MHS in each zone. For instance, the results of this study indicate that the South West has the highest proportion of adequate number of ANC visits (38\%) and institutional delivery (77\%), which is partially explained by the fact that the South West has the highest number of health facilities and skilled health workers (Health Reform Foundation of Nigeria, 2007). Further, the South West zone has the highest literacy rate (males and females) and the highest number of media outfits that support the sensitization of the populace (Health Reform Foundation of Nigeria, 2007; National Population Commission \& ICF Macro, 2009).

On the other hand, the North East geopolitical zone has the lowest proportion of women who had four or more ANC visits (22.9\%) and delivered in a health facility (14.2\%) due to having the lowest number of health resources, lowest literacy levels and lowest number of media outlets that support the education of the population (Health Reform Foundation of Nigeria, 2007; National Population Commission \& ICF Macro, 2009). The results of this study also indicate that other possible reasons for the poor state of health resources and population health outcome in the North West and North East zones is the fact that a significant proportion of the respondents reported that distance and lack of skilled health workers are major obstacles to access and use of MHS. This assertion is consistent with the finding of other studies that were conducted across the six geopolitical zones of Nigeria (Babalola \& Fatusi, 2009; Doctor, Bairagi, Findley, Helleringer, \& Dahiru, 2011; Fapohunda \& Orobaron, 2014; Fawole et al., 2012;).

The low utilization of MHS in the North West and North East zones observed in our study is consistent with other reports that indicated the North West and North East zones have the highest maternal and perinatal fetal deaths due to high prevalence of high risk pregnancies such as pregnant teenagers, pregnancies among women greater than 35 years, short interval between births, and grand multipara (Doctor et al., 2011; Fapohunda \& Orobaron, 2014; Fawole et al., 2012; Garba \& Umar, 2013). These high-risk pregnancies were similarly reported in areas with low utilization of MHS in other parts of Nigeria (Adeoye, Onayade, \& Fatusi, 2013) and developing countries (UNICEF, 2012; Yego, D’Este, Byles, Williams, \& Nyongesa, 2014). 
A combination of high-risk pregnancies, poor access, and use of MHS has contributed to placing Nigeria among the 12 countries that have neonatal deaths of $>45$ per 1,000 live births (Lawn, Causens, \& Zupan, 2005) and maternal mortality rate of $>600$ per 100,000 live births (WHO et al., 2010). The three geopolitical zones of Northern Nigeria have the lowest access and use of MHS and the highest infant mortality rate due poor distribution of health resources, ignorance, and poverty resulting in geographical, economic, cultural, and or technical barriers, as was similarly reported in South Africa (Wabiri, et al., 2013), Bangladesh (Anwar, Nababan, Mostari, Rahman, \& Khan, 2015), India (Saxena, Vangani, Mavalankar, \& Thomsen, 2013), and Ghana (Ganle, Parker, Fitzpatrick, \& Otupiri, 2014). These barriers marginalized pregnant women, particularly those in lowest income quartile due to their inability to bear the cost of modern health services (Coast et al., 2012; Ganle, et al., 2014; Obiechina \& Ekenedo, 2013; United Health Foundation, 2011).

ANC is an objective strategy to effectively identify high-risk pregnancies. However, the low proportion of women who had four or more number of ANC visits means that many high-risk pregnant women may not be detected and may result in life-threatening conditions and, in extreme cases, could lead to the death of a woman and/or her baby. The scenario is further compounded if such women deliver in homes or reach the hospital in moribund condition after several days in labor. A combination of these factors with low utilization rates for ANC and institutional delivery, as was observed in this study, may be one reason that the country is considered among the least safe places for a woman to bear children (WHO et al., 2010) and for a child to be born (Owais et al., 2013). Plausible reasons that could be advanced for low MHS patronage in this study are factors relating to availability and affordability of such services, because $70 \%$ of the Nigerian population lives in rural areas and live on less than USD $\$ 2$ per day (WHO, 2013).

\section{Conclusion}

Overall, the disparity in the use of MHS among the six geopolitical zones of Nigeria highlighted the differences that exist in health system resources within these zones and how individual and community norms and traditions influence the use of MHS. The differences in the distribution of resources was similarly observed even when the data was disaggregated by place of domicile (rural or urban), with rural areas having less likelihood of making the recommended number of ANC visits and delivery in a health facility. These differences by geopolitical zones of residence and place of domicile have underscored that women living in rural areas of North West and North East zones have a higher risk of maternal, morbidity, mortality, and disability compared to other geopolitical zones of Nigeria. It also highlighted the importance of taking into consideration the geopolitical zones and place of domicile in order to develop a holistic plan that addresses not only individual risk factors but also community level influence that are associated with access and use of MHS.

A long-term approach is to strengthen policies relating to universal basic education (Millennium Development Goal [MDG] 2) for girls in order to increase the uptake and ensure the retention up to completion of secondary (high) school. This will be pivotal towards reduction of poverty (MDG 1), gender equality (MDG 3), and the maternal (MDG 5) mortality. It will ultimately bridge the gap along the socioeconomic gradient between rural and urbans areas and enhance higher utilization rates of MHS.

In the short term, there is the need for systematic engagement and orientation of traditional birth attendants and other local volunteers in order to sensitize their respective communities on the benefits of ANC visits and delivery in health facility. Each of the traditional birth attendants and the local volunteers should be linked to a given health facility in order to share information on defaulters requiring follow up home visits aimed at getting them back to continue the use of MHS. Additionally, 
such an approach has potential to strengthen maternal health surveillance and the detection of any of the nationally notifiable diseases through simple field operational community case definitions that could facilitate the identification and notification of suspected cases by the community. There is the need for more in-depth study on perceived health needs of pregnant women and health care providers and the causes of delays to seek medical intervention. This information is not available in the DHS data used in this study.

\section{Limitations of the study}

This was a cross-sectional study. It did not prove causality; rather, it described the association between independent and dependent variables. The DHS data lacked information on the perception and misperception of women on the benefits of MHS, which could have partially influenced their use of MHS as observed in this study. There is the need for further studies that will address these limitations.

\section{References}

Adeoye, I. A., Onayade, A. A., \& Fatusi, A. O. (2013). Incidence, determinants and perinatal outcomes of near miss maternal morbidity in Ile-Ife Nigeria: A prospective case control study. BMC Pregnancy and Childbirth, 13, 93. doi:10.1186/1471-2393-13-93

Ahmed, S., Creanga, A. A., Gillespie, D. G., \& Tsui, A. O. (2010). Economic status, education and empowerment: Implication for maternal health services utilization in Developing countries. PLoS ONE, 5, e1190. doi:10.1371/journal.pone.0011190

Andersen, R. M. (1995). Revisiting the behavioral model and access to medical care: Does it matter? Journal of Health Social Behavior, 36, 1-10.

Andersen, R. M., \& Newman, J. F. (2005). Societal and individual determinants of medical care utilization in the United States. The MilBank Quarterly, 83, 1-28.

Antai, D. (2009). Faith and child survival: The role of religion in childhood immunization in Nigeria. Journal of Biosocial Science, 41, 57-76. doi:10.1017/S0021932008002861.

Anwar, I., Nababan, H. Y., Mostari, S., Rahman, A., \& Khan, J. A. M. (2015). Trends and Inequities in use of maternal health care services in Bangladesh, 1991-2011. PLoS ONE, 10, e0120309. doi:10.1371/journal.pone.0120309

Babalola, S., \& Fatusi, A. (2009). Determinants of use of maternal health services in Nigeria: Looking beyond individual and household factors. BMC Pregnancy and Childbirth, 9, 43. doi: 10.1186/1471-2393-9-43

Coast, E., McDaid, D., Leone, T., Pitchforth, E., Matthews, Z., Lemmi, V., \&N Jones, E. (2012). What are the effects of different models of delivery for improving maternal and infant health outcomes for poor people in urban areas in low income and lower middle income countries? London, United Kingdom: Department for International Development. Retrieved from http://eprints.lse.ac.uk/41908/1/What_are_the_effects_of_different_models_of_delivery_for_im proving_maternal_and_infant_outcomes_for_poor_people_in_urban_areas_in_low_income_an d_lower_middle_income_countries_\%28LSERO\%29.pdf

Doctor, H. V., Bairagi, R., Findley, S. E., Helleringer, S., \& Dahiru, T. (2011). Northern Nigeria, maternal, newborn, and child health program: Selected analysis from population based baseline study. The Open Demographic Journal, 4, 11-21. 
Ezugwu, E. C., Agu, P. U., Nwoke, M. O., \& Ezugwu, F. O. (2014). Reducing maternal deaths in poor resource setting in Nigeria. Nigerian Journal of Clinical Practice, 17, 62-66. doi:10.4103/1119-3077.122842.

Fapohunda, B. M., \& Orobaton, N. G. (2013). When women deliver with no one present in Nigeria: Who, what, where and so what? PLoS ONE, 8, e69569. doi:10.1371/journal.pone.0069569

Fapohunda, B., \& Orobaron, N. (2014). Factors influencing the selection of delivery with no one present in Northern Nigeria: Implications for policy and programs. International Journal of Women's Health, 6, 171-183. doi:10.2147/IJWH.S54628.

Fawole, A. O. Shah, A., Fabanwo, A. O., Adegbola, O., Adewunmi, A. A., Eniayewun, A. B., Dara, K., ... Sa'id, M. (2012). Predictors of maternal mortality in institutional deliveries in Nigeria. African Health Science, 12, 32-40. Retrieved from http://www.ncbi.nlm.nih.gov/pubmed/23066417

Ganle, J. K., Parker, M., Fitzpatrick, R., \& Otupiri, E. (2014). Inequities in accessibility to and utilisation of maternal health services in Ghana after user-fee exemption: A descriptive study. International Journal for Equity in Health, 13, 89. doi:10.1186/s12939-014-0089-z

Garba, J. A., \& Umar, S. (2013). Aetiology of maternal mortality using verbal autopsy at Sokoto, North western Nigeria. African Journal of Primary Health Care and Family Medicine, 5, 442. doi:10.4102/phcfm.v5i1.442

Health Reform Foundation of Nigeria. (2007). Primary health care in Nigeria: 30 years after AlmaAta. The Nigerian Health Review. Lagos, Nigeria: Mnat Educational Window Consultant Ltd.

Lawn, J. E., Causens, S., \& Zupan, J. (2005). 4 million neonatal deaths: when, where, why? The Lancet Neonatal Survival Series, 1, 18. Retrieved from http://www.who.int/maternal_child_adolescent/documents/pdfs/lancet_neonatal_survival_pap er1.pdf

Nakua, E. K., Sevugu, J. T., Dzomeku, V. M., Otupiri, E., Lipkovich, H. R., \& Owusu-Dabo, E. (2015). Home birth without skilled attendants despite millennium villages project intervention in Ghana: Insight from a survey of women's perceptions of skilled obstetric care. BMC Pregnancy and Childbirth, 15, 243. doi:10.1186/s12884-015-0674-1

National Population Commission \& ICF Macro. (2009). Nigeria Demographic and Health Survey 2008. Calverton, MD: National Population Commission and ICF Macro. Retrieved from http://pdf.usaid.gov/pdf_docs/PNADQ923.pdf

Nieburg, P. (2012). Improving maternal mortality and other aspects of women's health: The United States' global role. Washington DC: Center of Strategic and International Studies Retrieved from

https://www.google.com.ng/?gws_rd=cr\#q=Nieburg\%2C+P.+\%282012\%29.+Improving+mater nal+mortality+and+other+aspects+of+women $\% \mathrm{E} 2 \% 80 \% 99 \mathrm{~s}+$ health $\% 3 \mathrm{~A}+$ The+United+States $\% \mathrm{E} 2 \% 80 \% 99+$ global+role

Obiechina, G. O., \& Ekenedo, G. O. (2013). Factors affecting the utilization of university health services in a tertiary health institution in south west Nigeria. Nigerian Journal of Clinical Practice, 16, 454-457. doi:10.4103/1119-3077.116888

Owais, A., Faruque, A. G., Das, S. K., Ahmed, S., Rahman, S., \& Stein, A. D. (2013). Maternal and antenatal risk factors for stillbirths and neonatal mortality in rural Bangladesh: A casecontrol study. PLoS ONE, 8, e80164. doi:10.1371/journal.pone.0080164 
Saxena, D., Vangani, R., Mavalankar, D. V., \& Thomsen, S. (2013). Inequity in maternal health care service utilization in Gujarat: Analyses of district level health survey data. Global Health Action, 13, 6. doi:10.3402/gha.v6i0.19652

Shiferaw, S., Spigt, M., Godefrooij, M., Melkamu, Y., \& Tekie, M. (2013). Why do women prefer home births in Ethiopia? BMC Pregnancy and Childbirth, 13, 5. Retrieved from http://www.biomedcentral.com/1471-2393/13/5

Szklo, M., \& Nieto, F. J. (2014). Understanding a lack of validity: Bias in epidemiology: Beyond the basics (3rd ed.). Sudbury, MA: Jones and Bartlett.

UNICEF. (2009). Nigeria national report global study on child poverty and disparities. Retrieved from http://www.google.com.ng/url?sa=t\&rct=j\&q=\&esrc=s\&source=web\&cd=6\&ved=0CD4QFjAF \&url=http $\% 3 \mathrm{~A} \% 2 \mathrm{~F} \% 2 \mathrm{Fw} w$ w.unicef.org\%2Fsocialpolicy\%2Ffiles $\% 2 \mathrm{FNigeria}$ _GLOBAL_STU DY_ON_CHILD_POVERTY_AND_DISPARITIES_smaller.pdf\&ei=KaqiU6XVEuSv7AaiyoHg Dw\&usg=AFQjCNFYjDRacvW6-QZY9u0s1S_wtNr68A

UNICEF. (2012). State of the world's children 2012. New York, NY: Author. Retrieved from http://www.unicef.org/sowc2012/pdfs/SOWC-2012-Main- Report_EN_21Dec2011.pdf

United Health Foundation. (2011). America's health ranking: A call to action for individuals and their communities. Minnetonka, MN: Author. Retrieved from http://www.americashealthrankings.org/SiteFiles/Reports/AHR\%202011edition.pdf

Wabiri, N., Chersich, M., Zuma, K., Blaauw, D., Goudge, J., \& Dwane, N. (2013). Equity in maternal health in South Africa: Analysis of health service access and health status in a national household survey. PLoS ONE, 8, e73864. doi:10.1371/journal.pone.0073864

Wang, W., Alva, S., Wang, S., \& Fort, A. (2011). Levels and trends in the utilization of maternal health services in developing countries. Calverton, MD: ICF Macro. Retrieved from http://www.measuredhs.com/publications/publication-cr26-comparative-reports.cfm

World Health Organization (WHO). (2005). World health report 2005: Making every mother and child count. Geneva, Switzerland: Author. Retrieved from http://www.who.int/whr/2005/whr2005_en.pdf

World Health Organization (WHO). (2011). Evaluating the quality of care for severe pregnancy complications: The WHO near-miss approaches for maternal health. Geneva, Switzerland: Author. Retrieved from http://www.who.int/reproductivehealth/publications/monitoring/9789241502221/en/

World Health Organization (WHO). (2013). World health statistics 2013. WHO, Geneva, Switzerland. Retrieved from http://www.who.int/gho/publications/world_health_statistics/2013/en/

World Health Organization (WHO). (2015). Maternal health. Geneva, Switzerland: Author. Retrieved from http://www.measuredhs.com/Topics/Maternal-Health.cfm

World Health Organization (WHO). (2016a). WHO recommendations on antenatal care for a positive pregnancy experience. Geneva, Switzerland: Author. Retrieved from http://apps.who.int/iris/bitstream/10665/250796/1/9789241549912-eng.pdf?ua=1

World Health Organization (WHO). (2016b). World health statistics 2016: Monitoring health for SDGs. Geneva, Switzerland: Author. Retrieved from http://www.who.int/gho/publications/world_health_statistics/2016/en/ 
World Health Organization (WHO), UNICEF, United Nations Population Fund, \& the World Bank. (2010). Trends in maternal mortality: 1990 to 2008: Estimates developed by WHO, UNICEF, UNFPA, and the World Bank. Geneva, Switzerland: WHO. Retrieved from http://whqlibdoc.who.int/publications/2010/9789241500265_eng.pdf

Yego, F., D’Este, C., Byles, J., Williams, J. S., \& Nyongesa, P. (2014). Risk factors for maternal mortality in a tertiary hospital in Kenya: A case control study. BMC Pregnancy and Childbirth, 14, 38. doi:10.1186/1471-2393-14-38

The Journal of Social, Behavioral, and Health Sciences is an open-access, peer-reviewed, online interdisciplinary journal focusing on research findings that address contemporary national and international issues. Its objectives are to (a) encourage dialogue between scholars and practitioners in the social, behavioral, and health sciences that fosters the integration of research with practice; (b) promote innovative models of interdisciplinary collaboration among the social, behavioral, and health sciences that address complex social problems; and (c) inform the relationship between practice and research in the social, behavioral, and health sciences.

Walden University Publishing: http://www.publishing.waldenu.edu 